\title{
Endogenous Differential Mortality, Non- Contractible Effort and Non Linear Taxation
}

\author{
MARIE-LOUISE LEROUX \\ CESIFO WORKING PAPER NO. 2567 \\ CATEGORY 3: SOCIAL PROTECTION \\ MARCH 2009
}

An electronic version of the paper may be downloaded

- from the SSRN website:

- from the RePEc website:

- from the CESifo website:

www.SSRN.com

www.RePEc.org

www.CESifo-group.org/wp 


\title{
Endogenous Differential Mortality, Non- Contractible Effort and Non Linear Taxation
}

\begin{abstract}
This paper studies a problem of non linear taxation when individuals have different longevities resulting from a non-monetary effort (like exercising). We first present the laissezfaire and the first best. Like Becker and Philipson (1998), we find that the laissez-faire level of effort is too high compared with the first best, because individuals do not internalize the impact of survival on the return of their savings. We also claim that because of its nonmonetary form, effort is not contractible. That is why we modify our framework and assume, for the rest of the paper, that effort is determined by the individual while the social planner only allocates consumptions. It turns out that, under full information, a tax on the return of annuitized savings is desirable for both types. This tax is higher for the low-survival individual. Under asymmetric information, the low-survival individual still faces a tax while the high-survival individual might now face a positive or negative tax on annuities. Interestingly, our results depend on the value of life.
\end{abstract}

JEL Code: H21, H23, H55, I12.

Keywords: annuities, effort, differential mortality, non linear taxation, value of life.

\author{
Marie-Louise Leroux \\ CORE \\ Catholic University of Louvain \\ Voie du Roman Pays, 34 \\ 1348 Louvain-la-Neuve \\ Belgium \\ marie-louise.leroux@uclouvain.be
}

February 18, 2009

The author would like to thank Julio Davila, Jean- Marie Lozachmeur, François Maniquet, Pierre Pestieau and Grégory Ponthière for their comments and valuable remarks. 


\section{Introduction}

Is our life expectancy predetermined? To what extent can we influence it? Several factors determine human longevity. It may depend on intrinsic characteristics (such as gender or heredity) or on environmental and sociocultural factors. However, individuals may also be able to influence their longevities by making specific lifestyle choices. This can be achieved either through monetary investments (for example, undergoing expensive surgery) or through non-monetary ones. In this latter case, health-improving effort can equally be exercising, dieting, living a healthy life, sleeping eight hours a night, etc... For instance, Kaplan et al. (1987) show that little or no physical activity is associated with higher mortality risks at all ages. In a more recent study, Okamoto (2006) also finds a significantly positive relationship between leisure time spent in sports and the increase in life expectancy at 65 of Japanese men. ${ }^{1}$

Relating these questions to the current debates on Social Security, the factors influencing life duration and their consequences raise difficult issues for policy-makers. With regard to equity issues alone, several empirical studies (see e.g. Coronado et al. 2000, Liebman 2001 and Bommier et al. 2006) find that longevity differentials reduce intra-generational redistribution since Social Security systems provide an annuity which is independent of one's life duration. For instance, individuals with lower income obtain higher replacement rates, yet this redistribution is partly neutralized owing to the positive correlation between life expectancy and income. Consequently, longevity is one of the many dimensions, other than productivity, which should be included in pension schemes.

From a theoretical perspective, the contributions of Bommier et al. (2007a, b) discuss the optimal pension design when individuals have different longevities, which they assume to be exogenous. Under specific assumptions on individual preferences, they conclude that, in the first best optimum, short-lived individuals should be compensated for their unluckiness by getting higher per period

\footnotetext{
${ }^{1}$ More evidence on the relationship between physical activity and longevity can also be found in Ferucci et al. (1999), Franco et al. (2005, 2006).
} 
consumption and retiring earlier than long-lived individuals. ${ }^{2}$

In contrast, this paper studies a problem of optimal non linear taxation in an economy where individuals have different longevities as the result of a private (and costly) effort. We assume a two-period model in which surviving to the second period is uncertain and depends on the level of effort made in the first period. Individuals may yet differ in their disutility from effort so that they end up with different survival chances. Unlike Eeckhoudt and Pestieau (2006) and Becker and Philipson (1998), we also assume that individuals' effort takes a non-monetary form so that the social planner cannot influence it directly. Finally, unlike Bommier et al. (2007a, b), individuals' lifetime utility is additively separable; we decided to retain this standard formulation in order to emphasize the role of private efforts on the optimal allocation.

Under these assumptions, we first present the laissez-faire as a benchmark case and second we study a (hypothetical) first best problem in which the social planner allocates consumptions and efforts. The ensuing result is that the optimal level of effort is smaller in the first best than in the laissez-faire. This is what we refer to as the Becker-Philipson effect (referring to Becker and Philipson, 1998). In the laissez-faire, the individual invests too much in his longevity because he only takes into account the direct impact of effort on his survival without considering its indirect impact on the return of his savings through a lower annuity return. In order to solve this inefficiency, a tax on effort would be required, which, we claim, is not possible as effort is non-monetary. This is why in the following we resort to a framework in which effort is non-contractible.

In this modified set-up, individuals choose their effort level privately while the social planner can influence it only through the allocation of consumptions. Under full information, future consumption is always lower than present consumption as a way to make individuals exert less effort. We also demonstrate that the optimal allocation transfers resources from low-survival individuals to-

\footnotetext{
${ }^{2}$ they also question the modeling of individual preferences, when individuals face different life durations. Following Bommier (2006a, b), they show that with preferences à la Yaari (1965), individuals exhibit temporal risk neutrality, which leads to very specific and questionable conclusions in terms of redistribution. We will not discuss this point in the present paper.
} 
ward high-survival ones. Finally, we study the problem under asymmetric information, when the social planner cannot observe disutility from effort and effort levels. In this case, the distortion is identical to the full information one for the low-survival individual so that it is still optimal to encourage early consumption for this individual. On the other hand, for the high-survival individual, the Becker-Philipson effect and the incentive constraint act in opposite directions so that future consumption may be preferred to early consumption in some cases. Using a numerical example, we find that the overall distortion for this individual crucially depends on the gap between individuals' types and on the value of a statistical life. We also study how to decentralize these optima through a perfect annuity market and find that a tax on annuity is always optimal under full information with non-contractible effort. Under asymmetric information, it appears that a subsidy may be desirable in some cases for the individual with low disutility of effort as a way to relax the incentive constraint.

Interestingly, our paper states that, for reasons of efficiency, first period consumption should be preferred to second period consumption. This result appears as a convincing argument in favor of the observed patterns of replacement rates in actual Social Security systems. As shown by Gruber and Wise (1999), Social Security systems typically provide replacement rates which are lower than one. ${ }^{3}$ Our theoretical model supports such a feature of the pension design, as a way to limit longevity-enhancing behavior.

Finally, this paper is in line with the contribution of Sheshinski (2007) who briefly studies a similar problem. He showed that "under competition, there is excessive investment in increasing survival probabilities" because "individuals disregard the effect of their investments in (longevity) on the equilibrium rate of return on annuities". Our paper might however complete his work as we consider a special case of non-monetary investment in longevity; we also assume a population with different disutility from effort so that our results are not only about efficiency but also about equity.

\footnotetext{
${ }^{3}$ For example, they estimate that the replacement rate at early retirement age ranged from $20 \%$ in Canada to $91 \%$ in France and in the Netherlands.

${ }^{4}$ Chapter 7 pp.53 in "The economic theory of annuities".
} 
This paper is constructed as follows. In Section 2, we present the model and derive the laissez-faire and first best problems. In Section 3, we present a modified framework with full information and non-contractible effort. Section 4 sets out the results under asymmetric information and presents a numerical example. The last section concludes.

\section{The Model}

\section{$2.1 \quad$ Assumptions}

We consider a two-period model in which individuals live the first period with certainty and the second one with probability $\pi(e) \in[0,1]$ with $e$ being a private effort level. The survival probability $\pi($.$) takes the same form for all agents$ with $\pi^{\prime}()>0,. \pi^{\prime \prime}()<$.0 . We further assume that the elasticity of the survival probability with respect to effort, $\varepsilon_{\pi, e} \equiv \pi^{\prime}(e) e / \pi(e)$, is decreasing with effort. ${ }^{5}$ In our model, the individual's effort is made in first period and is non-monetary (such as exerting oneself in sport, dieting, living a healthy life) so that it does not enter into the individual's budget constraint. Exerting an effort, however, creates disutility which depends on the agent's taste for effort; this total utility cost is represented by $\gamma e$ where $\gamma$ represents the intensity of effort disutility.

The economy is composed of two groups of individuals, indexed by $i=1,2$ who have different intensities of effort disutility, $\gamma^{i}$. Each group represents a proportion $n^{i}$ of the population. We assume that $\gamma^{1}>\gamma^{2}$ so that type- 1 individuals are "bad-type" individuals since they have high disutility from effort while type-2 individuals are "good-type" individuals. There is no other source of heterogeneity and the initial wealth endowment $w$ is exogenous and identical for any individual.

The discount and interest rates are assumed to equal zero. The individual's lifetime welfare is additive over time and it depends on per period consumption and on total effort disutility. Assuming that the utility of being dead is normalized to zero, the expected lifetime utility of an individual with disutility of effort

\footnotetext{
${ }^{5}$ It is well known that in the case of physical activity, there is an optimal level of effort above which additional effort may effectively decrease the marginal gain from effort. In Section 3, we make more precise assumptions about the functional form of the survival function.
} 
$\gamma^{i}$ is given by:

$$
U^{i}(c, d, e)=u(c)+\pi(e) u(d)-\gamma^{i} e
$$

where $c$ and $d$ denote the consumptions in first and second period respectively. Per period utility of consumption, $u($.$) is such that u^{\prime}()>$.0 and $u^{\prime \prime}()<$.0 .

We also introduce here the notion of value of life. We define it as the price one would be ready to pay for an additional unit of life and we denote it $V L(c)$ in the rest of the paper. In Appendix A, we show that it is equal to

$$
V L(c)=\frac{u(c)-u^{\prime}(c) c}{u^{\prime}(c)}
$$

It is straightforward that $V L(c)$ is always increasing in $c$. We also assume that for all consumption levels that are considered we have $c u^{\prime}(c) / u(c)<1$, which ensures that the value of life is always positive. ${ }^{6}$ At this stage, it is also important to mention that there is no systematic correspondence between one's disutility from effort and his value of life. ${ }^{7}$

\subsection{The laissez-faire}

We assume that individuals invest all their savings in a perfect annuity market. An individual with type $\gamma^{i}$ determines his savings $s^{i}$ as well as his effort $e^{i}$ by solving the following problem:

$$
\begin{aligned}
& \max _{s^{i}, e^{i}} U^{i}\left(c^{i}, d^{i}, e^{i}\right)= u\left(c^{i}\right)+\pi\left(e^{i}\right) u\left(d^{i}\right)-\gamma^{i} e^{i} \\
& \text { s.to }\left\{\begin{array}{c}
c^{i}=w-s^{i} \\
d^{i}=R^{i} s^{i}
\end{array}\right.
\end{aligned}
$$

where $R^{i}$ is the return on savings, which is taken as given. Rearranging first order conditions yields: ${ }^{8}$

$$
\begin{aligned}
\frac{\pi\left(e^{i}\right) u^{\prime}\left(d^{i}\right)}{u^{\prime}\left(c^{i}\right)} & =\frac{1}{R^{i}} \\
\pi^{\prime}\left(e^{i}\right) & =\frac{\gamma^{i}}{u\left(d^{i}\right)}
\end{aligned}
$$

\footnotetext{
${ }^{6}$ On the notion of the value of life, see Murphy and Topel (2006) and Becker et al. (2005).

${ }^{7}$ An individual may have both a higher disutility from effort and a higher value of life.

${ }^{8}$ Under our assumptions, the Hessian of this problem is negative definite.
} 
The first condition gives the trade-off between present and future consumptions. Always assuming that insurers can perfectly observe individuals' survival probability and that the market for annuities is actuarially fair, the return $R^{i}$ from the annuity is $1 / \pi\left(e^{i}\right)$. Then, $u^{\prime}\left(c^{i}\right)=u^{\prime}\left(d^{i}\right)$ and the individual's consumption is smoothed across periods.

Condition (3) defines the individual's preferred level of effort, which is decreasing in $\gamma^{i}$. It states that at the optimal level, the expected marginal utility from increased life expectancy must be equal to marginal disutility from effort. Note that in the laissez-faire, the individual takes the annuity return as given so that he does not internalize the impact of his effort on the annuity return. This imperfection was first highlighted by Becker and Philipson (1998) who studied the trade-off between the quantity (i.e. longer lifetime) and the quality (i.e. fewer resources per period) of life and how individuals' attitude toward life extension affects mortality contingent claims. The intuition for their result is the following one. When choosing his longevity effort, the individual faces a free rider problem; he believes that he is one among a multitude of agents and that he cannot, by himself, influence the return of the annuity through his own survival. Since every individual from the same longevity risk category has the same belief, the annuity return is effectively modified. As will be shown in the rest of the paper, the laissez-faire level of effort is then generally too high compared with the optimal one. ${ }^{9}$

We finally compare individuals' laissez-faire allocations:

Proposition 1 When the annuity market is actuarially fair, the laissez-faire allocation is such that:

(i) $c^{1}=d^{1}>c^{2}=d^{2}$

(ii) $e^{1}<e^{2}$

\footnotetext{
${ }^{9}$ In their paper, Becker and Philipson (1998) conclude that "if it is not too costly to control most longevity-related behavior, private markets could almost internalize such external effects". To do so, they propose to implement a Pigouvian tax on longevity, equal to the social cost of the premium increase. We will see that, within the framework of our paper, using this mechanism is not possible.
} 
Point $(i i)$ is a direct consequence of (3) while point $(i)$ follows from our assumption of identical initial wealth. In this case, individuals with different $\gamma^{i}$ end up with identical expected lifetime consumption, defined as $c^{i}+\pi\left(e^{i}\right) d^{i} \equiv w$ $\forall i$. But, as consumption is smoothed across periods and $e^{1}<e^{2}$, the only possible allocations $\left(c^{1}, d^{1}\right)$ and $\left(c^{2}, d^{2}\right)$ which satisfy this equality are such that $c^{1}=d^{1}>c^{2}=d^{2}$.

\subsection{The first best problem}

Assume that the social planner is utilitarian and that he perfectly observes individuals' types. His problem amounts to maximizing

$$
\sum_{i=1,2} n^{i}\left[u\left(c^{i}\right)+\pi\left(e^{i}\right) u\left(d^{i}\right)-\gamma^{i} e^{i}\right]
$$

subject to the resource constraint of the economy,

$$
\sum_{i=1,2} n^{i}\left(c^{i}+\pi\left(e^{i}\right) d^{i}\right) \leq w
$$

First order conditions of this problem can be rearranged as: ${ }^{10}$

$$
\begin{aligned}
u^{\prime}\left(d^{i}\right) & =u^{\prime}\left(c^{i}\right) \\
\pi^{\prime}\left(e^{i}\right) u\left(d^{i}\right) & =\gamma^{i}+\pi^{\prime}\left(e^{i}\right) u^{\prime}\left(d^{i}\right) d^{i}
\end{aligned}
$$

It follows that consumption should be equalized across time and across agents so that $c^{i}=d^{i}=\bar{c}$. The second condition defines the optimal level of effort, $e^{i}$. Rearranging it as

$$
\pi^{\prime}\left(e^{i}\right)=\frac{\gamma^{i}}{u\left(d^{i}\right)}\left[\frac{u\left(d^{i}\right) / u^{\prime}\left(d^{i}\right)}{V L\left(d^{i}\right)}\right]
$$

and comparing it with (3), we see that it differs by a term $\left[\left(u\left(d^{i}\right) / u^{\prime}\left(d^{i}\right)\right) / V L\left(d^{i}\right)\right] \geqslant$ 1 , which reflects the impact of effort on the budget set. This is what we call in the rest of the paper the Becker-Philipson effect (BP effect): in the first best, the level of effort is lower than in the laissez-faire so as to take into account that longevity-enhancing behavior not only has an impact on the agent's survival but also on second period consumption possibilities through a tightened resource

\footnotetext{
${ }^{10}$ The Hessian of the problem is negative definite under our assumptions.
} 
constraint. Thus, at the optimal level of effort, the marginal gain in utility due to increased survival probability is equal to the total marginal cost of effort, that is the intensity of effort disutility plus marginal decrease in utility due to smaller consumption possibilities (see equation 4). This is summarized in the following proposition:

Proposition 2 For any type of individual, the first best level of effort is distorted downward with respect to the laissez-faire.

Note also that the size of the BP effect depends on the value of life. When $V L\left(d^{i}\right)$ increases, the term inside brackets tends to one so that the first best level of effort tends to the laissez-faire one. ${ }^{11}$ In other words, nothing is more important than being alive (even if the individual is let with no resources in the second period) and the BP effect only plays a marginal role. On the other hand, for smaller levels of the value of life $\left(V L\left(d^{i}\right) \rightarrow 0\right)$, life is worth living only because it creates consumption opportunities in the second period. In this case, the BP effect is important and so is the difference between the first best and the laissez-faire levels of effort.

Our second set of results concerns the allocation of consumptions and effort across individuals:

Proposition 3 Assume two groups of individuals, $i=1,2$ with effort disutility such that $\gamma^{1}>\gamma^{2}$. The first best allocation is characterized by

(i) $c^{i}=d^{i}=\bar{c} \forall i$,

(ii) $e^{1}<e^{2}$.

Point $(i)$ is a direct consequence of both utilitarianism and of additivity across periods in the individual's lifetime utility. The social planner also requires less effort from the individual with higher disutility of effort so that he ends up with a smaller survival probability. Since the expected lifetime consumption of an individual of type $\gamma^{i}$ is equal to $c^{i}+\pi\left(e^{i}\right) d^{i}$, one finds that this level is higher

\footnotetext{
${ }^{11}$ To see this, let us notice that the term inside brackets in (5) can be rewritten as $1 /\left[1-d^{i} u^{\prime}\left(d^{i}\right) / u\left(d^{i}\right)\right]$. When $d^{i} u^{\prime}\left(d^{i}\right) / u\left(d^{i}\right) \rightarrow 0$, this expression tends to one.
} 
for the low-disutility individual. Thus, the first best optimum transfers resources from low-survival individuals to high-survival ones.

Finally, we claim that this first best allocation cannot be decentralized through a simple tax-and-transfer scheme since effort is not contractible. ${ }^{12}$ This is a direct consequence of the non-monetary form of effort and this explains why in the following section we resort to a constrained first best in which the social planner lets individuals choose their effort and can influence it only through the allocation of consumptions.

\section{$3 \quad$ Full information with non-contractible effort}

\subsection{The optimum}

Since effort is not contractible, it is reasonable to assume that the social planner has no control over it. Thus, we now assume that the social planner only allocates consumptions, knowing that it may have consequences on individuals' choice of effort. In this section, the social planner perfectly observes individuals' types.

The timing of the problem is as follows. First, the social planner allocates consumptions and, second, individuals choose their level of effort. Proceeding by backward induction, we first solve the individual's problem. For each individual $i=1,2$, it amounts to maximizing (1) with respect to effort, taking as given the levels of first and second period consumptions. First order condition yields

$$
\pi^{\prime}\left(e^{i}\right) u\left(d^{i}\right)-\gamma^{i}=0
$$

This defines the preferred level of effort for this individual, which we denote as $e^{*}\left(\gamma^{i}, d^{i}\right)$ in the following. Not surprisingly, $e^{*}\left(\gamma^{i}, d^{i}\right)$ is decreasing in $\gamma^{i}$ and increasing in $d^{i}$. Then, the social planner chooses consumption paths for individuals of types $\gamma^{1}$ and $\gamma^{2}$ :

$$
\begin{aligned}
& \max _{c^{i}, d^{i}} \sum_{i=1,2} n^{i}\left[u\left(c^{i}\right)+\pi\left(e^{*}\left(\gamma^{i}, d^{i}\right)\right) u\left(d^{i}\right)-\gamma^{i} e^{*}\left(\gamma^{i}, d^{i}\right)\right] \\
& \text { s.to } \sum_{i=1,2} n^{i}\left[c^{i}+\pi\left(e^{*}\left(\gamma^{i}, d^{i}\right)\right) d^{i}\right] \leq w
\end{aligned}
$$

\footnotetext{
${ }^{12}$ We thank an anonymous referee for suggesting the term "contractible".
} 
First order conditions with respect to $c^{i}$ and $d^{i}$ are respectively:

$$
\begin{aligned}
u^{\prime}\left(c^{i}\right) & =\lambda \\
u^{\prime}\left(d^{i}\right) & =\lambda\left[1+\frac{\pi^{\prime}\left(e^{*}\left(\gamma^{i}, d^{i}\right)\right)}{\pi\left(e^{*}\left(\gamma^{i}, d^{i}\right)\right)} \frac{\partial e^{*}\left(\gamma^{i}, d^{i}\right)}{\partial d^{i}} d^{i}\right]
\end{aligned}
$$

where $\lambda$ is the Lagrange multiplier associated with the resource constraint. With non-contractible effort, present consumption should now be higher than future consumption. This is a direct consequence of both the BP effect and of the non-contractible form of effort: here, the only way to make individuals exert less effort is to provide them with less second period consumption. This result is summarized in the following proposition:

Proposition 4 Under full information with non-contractible effort, $c^{i}>d^{i}$ for any individual with type $\gamma^{i}$.

Substituting (7) into (8) and replacing the expression of $\partial e^{*}\left(\gamma^{i}, d^{i}\right) / \partial d^{i}$, we find that the gap between $c_{i}$ and $d_{i}$ depends on the value of life:

$$
\frac{u^{\prime}\left(d^{i}\right)}{u^{\prime}\left(c^{i}\right)}=1-\frac{\pi^{\prime}\left(e^{*}\left(\gamma^{i}, d^{i}\right)\right)^{2}}{\pi\left(e^{*}\left(\gamma^{i}, d^{i}\right)\right) \pi^{\prime \prime}\left(e^{*}\left(\gamma^{i}, d^{i}\right)\right)} \frac{d^{i}}{V L\left(d^{i}\right)+d^{i}}
$$

For a high level of $V L\left(d^{i}\right)$, the right-hand side tends to one so that $c^{i}$ and $d^{i}$ are close. In this case, the BP effect only plays a marginal role so that there is no need to encourage first period consumption with respect to second period consumption. On the contrary, if the value of life is small, this effect is important and the only way to correct for this inefficiency is to provide the individual with much higher levels of first period consumption.

We further study how consumptions should be allocated between individuals with different disutility from effort. According to equation (7), first period consumption is equalized between individuals, $c^{i}=\bar{c} \forall i$. On the other hand, second period consumption is differentiated since $\gamma^{i}$ enters in the RHS of (8). Assuming specific functional forms for $\pi(e)$ such that $\varepsilon_{\pi, e}$ is decreasing with effort, we show in Appendix B that second period consumption should be higher for the low-disutility individual. This is stated formally in the following proposition. 
Proposition 5 Consider two groups of individuals with types $\gamma^{1}$ and $\gamma^{2}$ such that $\gamma^{1}>\gamma^{2}$. Under full information with non-contractible effort,

(i) First period consumption is equalized across individuals, $c^{i}=\bar{c} \forall i$.

(ii) $d^{1}<d^{2}$ when individuals' survival probability is modeled as $\pi(e)=\log e$ or $\pi(e)=e /(1+e)$.

In this set-up, the optimal allocation transfers resources from the highdisutility, low-survival individual to the low-disutility, high-survival individual, since expected lifetime consumptions are such that $\bar{c}+\pi\left(e^{*}\left(\gamma^{2}, d^{2}\right)\right) d^{2}>\bar{c}+$ $\pi\left(e^{*}\left(\gamma^{1}, d^{1}\right)\right) d^{1}$.

\subsection{Decentralization}

Let us now consider how to decentralize the above optimum. In the following, we assume that instruments available to the social planner are individualized linear taxes on savings, $t^{i}$ and individualized lump sum transfers, $T^{i}$. Under our assumption that the annuity market is actuarially fair $\left(R^{i}=1 / \pi\left(e^{i}\right)\right)$, the individual's problem is to maximize:

$$
u\left(w-s^{i}\left(1+t^{i}\right)+T^{i}\right)+\pi\left(e^{i}\right) u\left(R^{i} s^{i}\right)-\gamma^{i} e^{i}
$$

The first order condition with respect to $s^{i}$ is

$$
\frac{u^{\prime}\left(d^{i}\right)}{u^{\prime}\left(c^{i}\right)}=1+t^{i}
$$

Comparing this condition with (9), we find that the first best allocation can be decentralized with a tax on saving equal to:

$$
t^{i}=-\frac{\pi^{\prime}\left(e^{*}\left(\gamma^{i}, d^{i}\right)\right)^{2}}{\pi\left(e^{*}\left(\gamma^{i}, d^{i}\right)\right) \pi^{\prime \prime}\left(e^{*}\left(\gamma^{i}, d^{i}\right)\right)} \frac{d^{i}}{V L\left(d^{i}\right)+d^{i}}>0
$$

Note that this tax is decreasing in the value of life. Indeed, a tax is required only to correct for the inefficiency created by the BP effect, which is smaller for higher levels of $V L\left(d^{i}\right)$.

The first best solution, as described by Proposition 5, can then be decentralized using taxes on annuities such that the level of the tax is higher for the 
individual with high disutility from effort, $t^{1}>t^{2}$. One also needs lump sum transfers from the low-survival toward the high-survival individual: $T^{1}<T^{2}{ }^{13}$

\section{Asymmetric information with non-contractible ef- fort}

\subsection{Theoretical results}

We now assume that the social planner neither observes individuals' disutility from effort nor their levels of effort. ${ }^{14}$ In this case, if the social planner proposes first best bundles, the individual with high disutility from effort $\left(\gamma^{1}\right)$ has an interest in claiming to have low disutility and to enjoy higher future consumption. ${ }^{15}$ To avoid mimicking behavior, we add an incentive constraint to the preceding problem:

$$
\begin{aligned}
& \max _{c^{1}, d^{1}, c^{2}, d^{2}} \sum_{i=1,2} n^{i}\left[u\left(c^{i}\right)+\pi\left(e^{*}\left(\gamma^{i}, d^{i}\right)\right) u\left(d^{i}\right)-\gamma^{i} e^{*}\left(\gamma^{i}, d^{i}\right)\right] \\
& \text { s.to }\left\{\begin{array}{c}
\sum_{i=1,2} n^{i}\left[c^{i}+\pi\left(e^{*}\left(\gamma^{i}, d^{i}\right)\right) d^{i}\right] \leq w \\
u\left(c^{1}\right)+\pi\left(e^{*}\left(\gamma^{1}, d^{1}\right)\right) u\left(d^{1}\right)-\gamma^{1} e^{*}\left(\gamma^{1}, d^{1}\right) \geq \\
u\left(c^{2}\right)+\pi\left(e^{*}\left(\gamma^{1}, d^{2}\right)\right) u\left(d^{2}\right)-\gamma^{1} e^{*}\left(\gamma^{1}, d^{2}\right)
\end{array}\right.
\end{aligned}
$$

We prove in Appendix $\mathrm{C}$ that the trade-offs between two-period consumptions for type 1 and type 2 are:

$$
\begin{aligned}
\frac{u^{\prime}\left(d^{1}\right)}{u^{\prime}\left(c^{1}\right)}= & \left(1-\frac{\pi^{\prime}\left(e^{*}\left(\gamma^{1}, d^{1}\right)\right)^{2}}{\pi\left(e^{*}\left(\gamma^{1}, d^{1}\right)\right) \pi^{\prime \prime}\left(e^{*}\left(\gamma^{1}, d^{1}\right)\right)} \frac{d^{1}}{V L\left(d^{1}\right)+d^{1}}\right) \\
\frac{u^{\prime}\left(d^{2}\right)}{u^{\prime}\left(c^{2}\right)}= & \left(1-\frac{\pi^{\prime}\left(e^{*}\left(\gamma^{2}, d^{2}\right)\right)^{2}}{\pi\left(e^{*}\left(\gamma^{2}, d^{2}\right)\right) \pi^{\prime \prime}\left(e^{*}\left(\gamma^{2}, d^{2}\right)\right)} \frac{d^{2}}{V L\left(d^{2}\right)+d^{2}}\right) \\
& \times\left[\frac{1-\frac{\mu}{n^{2}}}{1-\frac{\mu}{n^{2}} \frac{\pi\left(e^{*}\left(\gamma^{1}, d^{2}\right)\right)}{\pi\left(e^{*}\left(\gamma^{2}, d^{2}\right)\right)}}\right]
\end{aligned}
$$

\footnotetext{
${ }^{13}$ Note that in the special case of constant $\varepsilon_{\pi, e}=\varepsilon$, one has $d^{i}=\bar{d} \forall i$. In this case, taxes are identical across individuals and equal to

$$
t=\left(\frac{\varepsilon}{1-\varepsilon}\right) \frac{\bar{d}}{V L(\bar{d})}
$$

We still have $T^{1}<T^{2}$, but the size of these transfers is smaller than under decreasing elasticity.

${ }^{14}$ The social planner observes survival probabilities ex post but this does not give additional information on types since survival can always be the result of luck and not because the individual lied about his type.

${ }^{15}$ Note that, with constant elasticity, $\varepsilon_{\pi, e}=\varepsilon$, the first best allocation is still implementable under asymmetric information.
} 
where $\mu$ is the Lagrange multiplier associated with the incentive constraint. The first terms on the right-hand side of (10) and of (11) are similar to (9) and are greater than one. In (11), the additional term inside brackets results from the introduction of the incentive constraint and is lower than one since $\pi\left(e^{*}\left(\gamma^{1}, d^{2}\right)\right)<\pi\left(e^{*}\left(\gamma^{2}, d^{2}\right)\right)$. The trade-off between present and future consumptions is then equivalent to the full information case for the type- 1 individual. This is a kind of "no distortion at the top" result for the mimicker. Conversely, the second best allocation for a type- 2 individual is now distorted downward with respect to the full information case. Our results are summarized hereafter:

Proposition 6 Under asymmetric information with non-contractible effort,

(i) there is no distortion at the top for individuals of type $\gamma^{1}$ and $c^{1}>d^{1}$,

(ii) the trade-off between two-period consumptions is distorted downward for individuals of type $\gamma^{2}$ and $c^{2} \gtrless d^{2}$.

For the type $\gamma^{1}$, there is no additional distortion compared with the first best and $c^{1}>d^{1}$ simply to correct for the BP effect. On the other hand, the individual with low disutility from effort now faces two distortions with countervailing effects. To see this, let us first assume that there is no incentive problem; in this case, $\mu=0$ in (11) and $c^{2}>d^{2}$ as a result of the BP effect. Let us then consider a standard problem of asymmetric information $(\mu>0)$ where the BP effect is null; in this case, $c^{2}<d^{2}$. The intuition behind this result is as follows. Since the mimicker has high disutility from effort, he has lower chances to survive to the second period so that he prefers smaller levels of future consumption. It then makes sense to encourage future consumption for the mimickee as a way to relax an otherwise binding self-selection constraint. Later on in the paper, we call it the incentive effect.

Thus, if the BP effect dominates the incentive effect, early consumption should be encouraged with respect to future consumption for individual 2; yet, the difference between present and future consumption will be lower than in the full information case since the incentive effect partly neutralizes the BP effect. 
It is also possible that future consumption is preferred if the incentive effect dominates the BP effect.

Finally, we study how to implement these results. Comparing (10) and (11) with their laissez-faire counterparts, second best taxes now have the following expressions:

$$
\begin{gathered}
t^{1}=-\frac{\pi^{\prime}\left(e^{*}\left(\gamma^{1}, d^{1}\right)\right)^{2}}{\pi\left(e^{*}\left(\gamma^{1}, d^{1}\right)\right) \pi^{\prime \prime}\left(e^{*}\left(\gamma^{1}, d^{1}\right)\right)} \frac{d^{1}}{V L\left(d^{1}\right)+d^{1}}>0 \\
t^{2}=\left(1-\frac{\pi^{\prime}\left(e^{*}\left(\gamma^{2}, d^{2}\right)\right)^{2}}{\pi\left(e^{*}\left(\gamma^{2}, d^{2}\right)\right) \pi^{\prime \prime}\left(e^{*}\left(\gamma^{2}, d^{2}\right)\right)} \frac{d^{2}}{V L\left(d^{2}\right)+d^{2}}\right) \\
\times\left[\frac{1-\frac{\mu}{n^{2}}}{\left.1-\frac{\mu}{n^{2}} \frac{\pi\left(e^{*}\left(\gamma^{1}, d^{2}\right)\right)}{\pi\left(e^{*}\left(\gamma^{2}, d^{2}\right)\right)}\right]-1}\right.
\end{gathered}
$$

This tax has the same form as in the full information case for the high-disutility individual. Conversely, for the low-disutility individual, whether he faces a positive or negative tax now depends on the direction of the overall distortion. If the $\mathrm{BP}$ effect dominates the incentive effect, a positive tax on annuities is desirable. In the reverse case, he benefits from a subsidy (negative tax) on annuities and future consumption is encouraged.

In the next subsection, we simulate our model and study how the direction of the overall distortion depends on the distance between types $\left(\gamma^{1}-\gamma^{2}\right)$ and on individuals' preference parameters.

\subsection{Numerical example}

The objective of this section is to illustrate our previous theoretical results and to evaluate the size of the second best distortion for the type- 2 individual as a function of the parameters of the model.

Consider the following specifications for the various components of our model. Types $\left(\gamma^{1}, \gamma^{2}\right)$ are distributed on $\left.] 0,1\right]$ and we set $w=10$. The utility function has the following form, $u(c)=c^{\varepsilon} / \varepsilon$ with constant elasticity, $\varepsilon$. As a benchmark, we set $\varepsilon=0.2$ and $\gamma^{1}=1$. The survival probability is modeled as $\pi(e)=e /(1+e)$ which ensures that it is always lower than one and that it has decreasing elasticity. In the first table, we present the values of consumptions, 
efforts and survival probabilities for both types of individuals, under successively full information (FI) and asymmetric information (AI):

\begin{tabular}{|l||r||l|l|l|l|l|}
\hline & & $c$ & $d$ & $e$ & $\pi(e)$ & $\frac{u^{\prime}\left(d^{i}\right)}{u^{\prime}\left(c^{i}\right)}$ \\
\hline \hline$\gamma^{1}=1$ & individual 1 FI & 6.281 & 5.840 & 1.668 & 0.625 & 1.060 \\
\hline & AI & 6.956 & 6.475 & 1.695 & 0.629 & 1.059 \\
\hline$\gamma^{2}=0.9$ & individual 2 FI & 6.281 & 5.874 & 1.814 & 0.645 & 1.055 \\
\hline & AI & 5.606 & 5.255 & 1.782 & 0.641 & 1.053 \\
\hline & & & & & & \\
\hline$\gamma^{1}=1$ & individual 1 FI & 5.806 & 5.394 & 1.647 & 0.622 & 1.061 \\
\hline & AI & 6.694 & 6.229 & 1.685 & 0.628 & 1.059 \\
\hline$\gamma^{2}=0.1$ & individual 2 FI & 5.806 & 5.710 & 7.417 & 0.881 & 1.013 \\
\hline & AI & 4.920 & 5.088 & 7.320 & 0.880 & 0.974 \\
\hline
\end{tabular}

Table 1: Optimal allocations with non-contractible effort

In the above table, we assume that individuals have either very similar or very different disutility from effort. This table confirms the findings of Proposition 5 that under full information, future consumption is always higher for type-2 individuals. These results are yet more interesting when we study the optimal allocations under asymmetric information. First period consumption is no longer smoothed between individuals and those with high disutility now get higher present and future consumption levels; they also exert lower effort but have lower survival probability. In the last column, we present the distortion levels. As expected, early consumption is always encouraged for type-1 individuals. For type-2 individuals, we find that the level of the distortion under asymmetric information is always lower than under full information but whether it is greater or lower than one depends on the distance between the $\gamma \mathrm{s}$. For very close levels of the $\gamma \mathrm{s}$, the distortion is greater than one; the BP effect dominates the incentive effect and early consumption is preferred. On the other hand, when individuals' types are very different, the distortion is lower than one and we observe the reverse.

In order to verify our conjectures on the possible link between distance in types and the size of the distortion, the following table gives the values of the distortion for a type-2 individual when $\gamma^{2}$ varies: 


\begin{tabular}{|l||l|l|l|l|l|l|l|l|l|}
\hline$\gamma^{2}$ & 0.9 & 0.8 & 0.7 & 0.6 & 0.5 & 0.4 & 0.3 & 0.2 & 0.1 \\
\hline$u^{\prime}\left(d^{2}\right) / u^{\prime}\left(c^{2}\right)$ & 1.053 & 1.045 & 1.037 & 1.028 & 1.019 & 1.010 & 1.0 & 0.988 & 0.974 \\
\hline
\end{tabular}

Table 2: Distortion levels for a type-2 individual under asymmetric information

As expected, the distance between types plays a crucial role in determining the size of the distortion under asymmetric information. Indeed, for a given level of the BP effect, the higher the distance between types, the smaller the overall distortion for a type- 2 individual and the more likely it is to be lower than one. The explanation is as follows. If the distance in types increases, so does the difference between $d^{1}$ and $d^{2}$ in the first best. In this case, the highdisutility individual is more tempted to mimic the low-disutility individual and the incentive effect might be more "constraining". From $\gamma^{2}=0.3$, the incentive effect dominates the BP effect, the overall distortion is smaller than one and $d^{2}>c^{2}$.

Another important determinant of the distortion for this individual is the value of life, through its impact on the BP effect. With our specifications, $V L\left(d^{2}\right)=(1-\varepsilon) d^{2} / \varepsilon$. In the following table, we compute the distortion for different levels $\varepsilon:^{16}$

\begin{tabular}{|l||l|l|l|l|}
\hline$\varepsilon$ & $c^{2}$ & $d^{2}$ & $V L\left(d^{2}\right)$ & $\frac{u^{\prime}\left(d^{2}\right)}{u^{\prime}\left(c^{2}\right)}$ \\
\hline \hline 0.08 & 1.25 & 1.64 & 18.86 & 0.78 \\
\hline 0.1 & 2.40 & 2.71 & 24.38 & 0.90 \\
\hline 0.2 & 5.33 & 5.20 & 20.80 & 1.02 \\
\hline 0.3 & 6.29 & 5.77 & 13.46 & 1.06 \\
\hline 0.5 & 6.90 & 5.50 & 5.50 & 1.12 \\
\hline 0.6 & 7.10 & 5.02 & 3.35 & 1.15 \\
\hline
\end{tabular}

Table 3: Second best distortions for a type-2 individual as a function of espilon

Note that the value of life is increasing in $d^{2}$ and decreasing in $\varepsilon$, which explains why, in the above table, the value of life is first increasing and then decreasing. Thus, when $\varepsilon$ increases, the value of life decreases (not accounting for the variation in consumption), so that the inefficiency created by the BP effect increases. This results in a higher level of the overall distortion. For $\varepsilon \geqslant 0.2$,

\footnotetext{
${ }^{16}$ We assume $\gamma^{2}=0.5$.
} 
the $\mathrm{BP}$ effect dominates the incentive effect and first period consumption is encouraged.

\section{Concluding Remarks}

This paper studies an optimal taxation problem in which it is assumed that individuals can influence their longevity by exerting efforts. We first highlight the relations between effort, survival probability and the annuity return and show that, as in Becker-Philipson (1998), for any individual, the laissez-faire level of effort is too high compared with the first best one. This inefficiency arises because in the laissez-faire, the individual does not integrate the consequence of higher effort in his budget constraint. In this paper, we also assume that effort is non-monetary so that it is non-contractible. Thus, the individual privately chooses his level of effort while the social planner allocates consumptions. The following table provides a summary of our results.

\begin{tabular}{|c|c|c|c|}
\hline & Consumptions & Effort & Survival Proba. \\
\hline Laissez-Faire & $c^{1}=d^{1}>c^{2}=d^{2}$ & & \\
& \multirow{3}{*}{ First Best } & $c^{1}=d^{1}=c^{2}=d^{2}$ & \\
\cline { 1 - 2 } & \multirow{2}{*}{$\pi^{1}<e^{2}$} & \\
\cline { 1 - 2 } non-contractible, Full Info & $d^{1}<d^{2}<c^{1}=c^{2}$ & \\
\cline { 1 - 2 } non-contractible, Assym. Info & $c^{1}>c^{2}, d^{1}>d^{2}, c^{1}>d^{1}$ \\
$c^{2} \gtrless d^{2}$ & & \\
\hline
\end{tabular}

Table 4: Recapitulative table

We further studied how to decentralize these optima through a tax-andtransfer scheme. In our framework, under full information, it is optimal to tax annuitized savings and the level of the tax should be higher for the individual with higher disutility and thus lower survival. Under asymmetric information, a tax on annuities is still desirable for this latter individual. It turns out that, in some cases, it is optimal to subsidize savings for the individual with low disutility and high survival. Whether savings should be taxed or subsidized for this individual depends on whether the BP effect or the incentive effect dominates.

There are several directions in which the model could be extended. First, 
one main message of this paper consists in taxing savings as a way to limit nonmonetary investments in longevity. This result might be somewhat surprising and one might instead want to subsidize health investments. One clear reason is that, generally, individuals with worse health conditions are also the ones with lower resources so that subsidizing health for these agents is a way to redistribute income. Therefore, a first extension would be to introduce differences in wages; this would surely mitigate our results. ${ }^{17} \mathrm{~A}$ second direction is to make life expectancy also depend on intrinsic characteristics (such as gender); since efforts and genetics may be correlated, how would this additional characteristic modify our model? Finally, we assume additively separable preferences which imply temporal risk neutrality. Relaxing this assumption may modify our results substantially. Answering these questions is on our research agenda.

\footnotetext{
${ }^{17}$ Cremer et al. (2008) also justify health subsidization by invoking individuals myopia. Individuals may consume "sin goods" in the first periods of their life without realizing that it will have negative consequences on their health. A paternalistic government would like to tax sin goods and to subsidize health investments so as to compensate for the negative effects of these goods. In our model, individuals perfectly anticipate their longevity.
} 


\section{References}

[1] Becker, G.S., \& Philipson, T. (1998). Old-age longevity and mortality contingent claims. The Journal of Political Economy, 106(3), 551-573.

[2] Becker, G.S., Philipson, T.J, \& Soares, R.R. (2005). The quantity and quality of life and the evolution of world inequality. American Economic Review, $95(1), 277-291$.

[3] Bommier, A., Leroux, M-L., \& J-M. Lozachmeur (2007a). Differential Mortality and Social Security. IDEI Mimeo.

[4] Bommier, A., Leroux, M-L., \& J-M. Lozachmeur, 2007b. Uncertain Lifetime, Redistribution and non linear Pricing of Annuities. IDEI Mimeo.

[5] Bommier, A. (2006a). Uncertain lifetime and intertemporal choice: risk aversion as a rationale for time discounting. International Economic Review $47(4), 1223-1246$.

[6] Bommier, A. (2006b). Mortality, time preference and life-cycle models. Working paper.

[7] Bommier, A., Magnac, T., Rapoport, B., \& Roger, M. (2006). Droit à la retraite et mortalité différentielle. Economie et Prévision, 168, 1-16.

[8] Coronado, J.L, Fullerton, D., \& Glass, T. (2000). The progressivity of Social Security. NBER Working Paper 7520.

[9] Cremer, H., De Donder, P., Maldonado, D., \& Pestieau, P. (2008). Taxing sin goods and subsidizing health care. CORE Discussion Paper 2008/31.

[10] Cremer, H., Lozachmeur, J-M., \& Pestieau, P. (2004). Social security, retirement age and optimal income taxation. Journal of Public Economics, $88,2259-2281$.

[11] Eeckhoudt, L., \& Pestieau, P. (2007). Fear of ruin and longevity enhancing investment. Core Discussion Paper 2007/32. 
[12] Ferucci, L., Izmirlian, G., Leveille, S., Phillips, C., Corti, M-C, Brock, D., \& Guralnik, J. (1999). Smoking, physical activity and active life expectancy. American Journal of Epidemiology, 149(7), 645-653.

[13] Franco, O., de Laet, C., Peeters, A., Jonker, J., Makenbach, J., \&Nusselder, W. (2005). Effect of physical activity on life expectancy with cardiovascular disease. Archive of Internal Medicine, 165(20), 2355-2360.

[14] Franco, O., de Laet, C., Peeters, A., Jonker, J., Makenbach J., \& Nusselder, W. (2006). Physical activity and life expectancy with and without diabetes. Diabetes Care, 29(1), 38-43.

[15] Gruber, J., \& Wise, D. (1999). Social Security and retirement around the world. Chicago University Press, Chicago.

[16] Kaplan, G.A, Seeman, T.E., Cohen, R.D., Knudsen, L.P., \& Guralnik, J. (1987). Mortality among the elderly in the Alameda county study: behavioral and demographic risk factors. American Journal of Public Health, $77(3), 307-312$.

[17] Liebman, J.B. (2001). Redistribution in the current U.S Social Security system. NBER Working Paper 8625.

[18] Murphy, K.M, \& Topel, R.H. (2006). The value of health and longevity. Journal of Political Economy, 114(5), 871-904.

[19] Okamoto, K. (2006). Life expectancy at the age of 65 years and environmental factors: an ecological study in Japan. Archives of Gerontology and Geriatrics, 43, 85-91.

[20] Sheshinski, E. (2007). The economic theory of annuities. Princeton University Press.

[21] Yaari, M. (1965). Uncertain lifetime, life insurance and the theory of the consumer. The Review of Economic Studies, 32(2), 137-150. 


\section{Appendix}

\section{A Value of life}

Consider an individual with preferences similar to the ones described in Section

2. The only difference is that his survival probability now depends not only on a non-monetary effort, $e$ but also on some monetary investment, $m$. His survival probability is denoted $\pi(m, e)$ and his problem amounts to choosing optimal levels of consumptions in first and second periods $c$ and $d$ as well as the optimal levels of monetary and non-monetary efforts:

$$
\begin{aligned}
& \max u(c)+\pi(m, e) u(d)-\gamma e \\
& \text { s.to } c+\pi(m) d+m \leq w
\end{aligned}
$$

First order conditions yield

$$
\begin{aligned}
u^{\prime}(c) & =u^{\prime}(d)=\lambda \\
\pi_{e}(m, e) u(d)-\gamma & =0 \\
\pi_{m}(m, e) u(d) & =\lambda\left[1+\pi_{m}(m, e) d\right]
\end{aligned}
$$

Defining the value of life as the price this individual would be ready to pay for one additional unit of life, $V L$ is simply equal to $1 / \pi_{m}(m, e)$. From the above, we obtain (2).

\section{B Full information with non-contractible effort}

The Lagrangian of the problem is

$£=\sum_{i=1,2} n^{i}\left[u\left(c^{i}\right)+\pi\left(e^{*}\left(\gamma^{i}, d^{i}\right)\right) u\left(d^{i}\right)-\gamma^{i} e^{*}\left(\gamma^{i}, d^{i}\right)\right]+\lambda\left[w-\sum_{i=1,2} n^{i}\left[c^{i}+\pi\left(e^{*}\left(\gamma^{i}, d^{i}\right)\right) d^{i}\right]\right]$

First order conditions with respect to $c^{i}$ and $d^{i}$ are:

$$
\begin{aligned}
& u^{\prime}\left(c^{i}\right)-\lambda=0 \\
& u^{\prime}\left(d^{i}\right)-\lambda\left[1+\frac{\pi^{\prime}\left(e^{*}\left(\gamma^{i}, d^{i}\right)\right)}{\pi\left(e^{*}\left(\gamma^{i}, d^{i}\right)\right)} d^{i} \frac{\partial e^{*}\left(\gamma^{i}, d^{i}\right)}{\partial d^{i}}\right]=0
\end{aligned}
$$


Fully differentiating (6), we find that

$$
\frac{\partial e^{*}\left(\gamma^{i}, d^{i}\right)}{\partial d^{i}}=-\frac{\pi^{\prime}\left(e^{*}\left(\gamma^{i}, d^{i}\right)\right) u^{\prime}\left(d^{i}\right)}{\pi^{\prime \prime}\left(e^{*}\left(\gamma^{i}, d^{i}\right)\right) u\left(d^{i}\right)}>0
$$

and replacing it in (12), we obtain

$$
u^{\prime}\left(d^{i}\right)-\lambda\left[1-\frac{\pi^{\prime}\left(e^{*}\left(\gamma^{i}, d^{i}\right)\right)^{2}}{\pi\left(e^{*}\left(\gamma^{i}, d^{i}\right)\right) \pi^{\prime \prime}\left(e^{*}\left(\gamma^{i}, d^{i}\right)\right)} \frac{u^{\prime}\left(d^{i}\right) d^{i}}{u\left(d^{i}\right)}\right]=0
$$

Assuming that $\pi(e)=\log e$ with $e \in[1, \exp ]$, the above expression becomes

$$
u^{\prime}\left(d^{i}\right)-\lambda\left[1+\frac{1}{\pi\left(e^{*}\left(\gamma^{i}, d^{i}\right)\right)} \frac{u^{\prime}\left(d^{i}\right) d^{i}}{u\left(d^{i}\right)}\right]=0
$$

Using the implicit function theorem, one has

$$
\operatorname{sign}\left(\frac{d d^{i}}{d \gamma^{i}}\right)=\operatorname{sign}\left(\frac{\partial\left(u^{\prime}\left(d^{i}\right)-\lambda\left[1+\frac{1}{\pi\left(e^{*}\left(\gamma^{i}, d^{i}\right)\right)} \frac{u^{\prime}\left(d^{i}\right) d^{i}}{u\left(d^{i}\right)}\right]\right)}{\partial \gamma^{i}}\right)
$$

where the expression on the right-hand side is equal to

$$
\lambda \frac{u^{\prime}\left(d^{i}\right) d^{i}}{u\left(d^{i}\right)} \frac{\pi^{\prime}\left(e^{*}\left(\gamma^{i}, d^{i}\right)\right)}{\pi\left(e^{*}\left(\gamma^{i}, d^{i}\right)\right)^{2}} \frac{\partial e^{*}\left(\gamma^{i}, d^{i}\right)}{\partial d^{i}}
$$

which is negative, since $\partial e^{*}\left(\gamma^{i}, d^{i}\right) / \partial \gamma^{i}<0$. Thus, $d^{1}<d^{2}$ for $\gamma^{1}>\gamma^{2}$.

Assume now that $\pi(e)=e /(1+e)$. Equation (13) is now equal to

$$
u^{\prime}\left(d^{i}\right)-\lambda\left[1+\frac{1}{2 e^{*}\left(\gamma^{i}, d^{i}\right)} \frac{u^{\prime}\left(d^{i}\right) d^{i}}{u\left(d^{i}\right)}\right]=0
$$

Again using the implicit function theorem, one obtains that $d d^{i} / d \gamma^{i}<0$ so that $d^{1}<d^{2}$ for $\gamma^{1}>\gamma^{2}$.

Note finally that if $\pi(e)$ has constant elasticity with respect to effort, denoted $\varepsilon$ with $\varepsilon<1$, equation (13) becomes

$$
u^{\prime}\left(d^{i}\right)-\lambda\left[1-\frac{\varepsilon}{\varepsilon-1} \frac{u^{\prime}\left(d^{i}\right) d^{i}}{u\left(d^{i}\right)}\right]=0
$$

so that first order condition on $d^{i}$ is independent of individual's types and $d^{1}=d^{2}$ for $\gamma^{1}>\gamma^{2}$. 


\section{Asymmetric information with non-contractible ef- fort}

The Lagrangian of the problem under asymmetric information is

$$
\begin{aligned}
£\left(c^{1}, c^{2}, d^{1}, d^{2}\right)= & \sum_{i=1,2} n^{i}\left[u\left(c^{i}\right)+\pi\left(e^{*}\left(\gamma^{i}, d^{i}\right)\right) u\left(d^{i}\right)-\gamma^{i} e^{*}\left(\gamma^{i}, d^{i}\right)\right] \\
& +\lambda\left\{w-\sum_{i=1,2} n^{i}\left[c^{i}+\pi\left(e^{*}\left(\gamma^{i}, d^{i}\right)\right) d^{i}\right]\right\} \\
& +\mu\left\{\begin{array}{c}
u\left(c^{1}\right)+\pi\left(e^{*}\left(\gamma^{1}, d^{1}\right)\right) u\left(d^{1}\right)-\gamma^{1} e^{*}\left(\gamma^{1}, d^{1}\right) \\
-u\left(c^{2}\right)-\pi\left(e^{*}\left(\gamma^{1}, d^{2}\right)\right) u\left(d^{2}\right)+\gamma^{1} e^{*}\left(\gamma^{1}, d^{2}\right)
\end{array}\right\}
\end{aligned}
$$

First order conditions can be rearranged as:

$$
\begin{aligned}
& u^{\prime}\left(c^{1}\right)\left(1+\frac{\mu}{n^{1}}\right)=\lambda \\
& u^{\prime}\left(c^{2}\right)\left(1-\frac{\mu}{n^{2}}\right)=\lambda \\
& u^{\prime}\left(d^{1}\right)\left(1+\frac{\mu}{n^{1}}\right)=\lambda\left[1+\frac{\pi^{\prime}\left(e^{*}\left(\gamma^{1}, d^{1}\right)\right)}{\pi\left(e^{*}\left(\gamma^{1}, d^{1}\right)\right)} \frac{\partial e^{*}\left(\gamma^{1}, d^{1}\right)}{\partial d^{1}} d^{1}\right] \\
& u^{\prime}\left(d^{2}\right)=\frac{\lambda}{1-\frac{\mu}{n^{2}} \frac{\pi\left(e^{*}\left(\gamma^{1}, d^{2}\right)\right)}{\pi\left(e^{*}\left(\gamma^{2}, d^{2}\right)\right)}}\left[1+\frac{\pi^{\prime}\left(e^{*}\left(\gamma^{2}, d^{2}\right)\right)}{\pi\left(e^{*}\left(\gamma^{2}, d^{2}\right)\right)} \frac{\partial e^{*}\left(\gamma^{2}, d^{2}\right)}{\partial d^{2}} d^{2}\right]
\end{aligned}
$$

In expressions (16) and (17), we first replace for the expression of $\partial e^{*}\left(\gamma^{i}, d^{i}\right) / \partial d^{i}$ (see its expression in Appendix B). Then, we obtain (10) by substituting (14) into (16). By the same procedure, we obtain (11) by substituting (15) into (17). 


\section{CESifo Working Paper Series}

for full list see www.cesifo-group.org/wp

(address: Poschingerstr. 5, 81679 Munich, Germany, office@cesifo.de)

2505 Wenan Fei, Claude Fluet and Harris Schlesinger, Uncertain Bequest Needs and LongTerm Insurance Contracts, December 2008

2506 Wido Geis, Silke Uebelmesser and Martin Werding, How do Migrants Choose their Destination Country? An Analysis of Institutional Determinants, December 2008

2507 Hiroyuki Kasahara and Katsumi Shimotsu, Sequential Estimation of Structural Models with a Fixed Point Constraint, December 2008

2508 Barbara Hofmann, Work Incentives? Ex Post Effects of Unemployment Insurance Sanctions - Evidence from West Germany, December 2008

2509 Louis Hotte and Stanley L. Winer, The Demands for Environmental Regulation and for Trade in the Presence of Private Mitigation, December 2008

2510 Konstantinos Angelopoulos, Jim Malley and Apostolis Philippopoulos, Welfare Implications of Public Education Spending Rules, December 2008

2511 Robert Orlowski and Regina T. Riphahn, The East German Wage Structure after Transition, December 2008

2512 Michel Beine, Frédéric Docquier and Maurice Schiff, International Migration, Transfers of Norms and Home Country Fertility, December 2008

2513 Dirk Schindler and Benjamin Weigert, Educational and Wage Risk: Social Insurance vs. Quality of Education, December 2008

2514 Bernd Hayo and Stefan Voigt, The Relevance of Judicial Procedure for Economic Growth, December 2008

2515 Bruno S. Frey and Susanne Neckermann, Awards in Economics - Towards a New Field of Inquiry, January 2009

2516 Gregory Gilpin and Michael Kaganovich, The Quantity and Quality of Teachers: A Dynamic Trade-off, January 2009

2517 Sascha O. Becker, Peter H. Egger and Valeria Merlo, How Low Business Tax Rates Attract Multinational Headquarters: Municipality-Level Evidence from Germany, January 2009

2518 Geir H. Bjønnes, Steinar Holden, Dagfinn Rime and Haakon O.Aa. Solheim, ,Large’ vs. ,Small' Players: A Closer Look at the Dynamics of Speculative Attacks, January 2009

2519 Jesus Crespo Cuaresma, Gernot Doppelhofer and Martin Feldkircher, The Determinants of Economic Growth in European Regions, January 2009 
2520 Salvador Valdés-Prieto, The 2008 Chilean Reform to First-Pillar Pensions, January 2009

2521 Geir B. Asheim and Tapan Mitra, Sustainability and Discounted Utilitarianism in Models of Economic Growth, January 2009

2522 Etienne Farvaque and Gaël Lagadec, Electoral Control when Policies are for Sale, January 2009

2523 Nicholas Barr and Peter Diamond, Reforming Pensions, January 2009

2524 Eric A. Hanushek and Ludger Woessmann, Do Better Schools Lead to More Growth? Cognitive Skills, Economic Outcomes, and Causation, January 2009

2525 Richard Arnott and Eren Inci, The Stability of Downtown Parking and Traffic Congestion, January 2009

2526 John Whalley, Jun Yu and Shunming Zhang, Trade Retaliation in a Monetary-Trade Model, January 2009

2527 Mathias Hoffmann and Thomas Nitschka, Securitization of Mortgage Debt, Asset Prices and International Risk Sharing, January 2009

2528 Steven Brakman and Harry Garretsen, Trade and Geography: Paul Krugman and the 2008 Nobel Prize in Economics, January 2009

2529 Bas Jacobs, Dirk Schindler and Hongyan Yang, Optimal Taxation of Risky Human Capital, January 2009

2530 Annette Alstadsæter and Erik Fjærli, Neutral Taxation of Shareholder Income? Corporate Responses to an Announced Dividend Tax, January 2009

2531 Bruno S. Frey and Susanne Neckermann, Academics Appreciate Awards - A New Aspect of Incentives in Research, January 2009

2532 Nannette Lindenberg and Frank Westermann, Common Trends and Common Cycles among Interest Rates of the G7-Countries, January 2009

2533 Erkki Koskela and Jan König, The Role of Profit Sharing in a Dual Labour Market with Flexible Outsourcing, January 2009

2534 Tomasz Michalak, Jacob Engwerda and Joseph Plasmans, Strategic Interactions between Fiscal and Monetary Authorities in a Multi-Country New-Keynesian Model of a Monetary Union, January 2009

2535 Michael Overesch and Johannes Rincke, What Drives Corporate Tax Rates Down? A Reassessment of Globalization, Tax Competition, and Dynamic Adjustment to Shocks, February 2009 
2536 Xenia Matschke and Anja Schöttner, Antidumping as Strategic Trade Policy Under Asymmetric Information, February 2009

2537 John Whalley, Weimin Zhou and Xiaopeng An, Chinese Experience with Global 3G Standard-Setting, February 2009

2538 Claus Thustrup Kreiner and Nicolaj Verdelin, Optimal Provision of Public Goods: A Synthesis, February 2009

2539 Jerome L. Stein, Application of Stochastic Optimal Control to Financial Market Debt Crises, February 2009

2540 Lars P. Feld and Jost H. Heckemeyer, FDI and Taxation: A Meta-Study, February 2009

2541 Philipp C. Bauer and Regina T. Riphahn, Age at School Entry and Intergenerational Educational Mobility, February 2009

2542 Thomas Eichner and Rüdiger Pethig, Carbon Leakage, the Green Paradox and Perfect Future Markets, February 2009

2543 M. Hashem Pesaran, Andreas Pick and Allan Timmermann, Variable Selection and Inference for Multi-period Forecasting Problems, February 2009

2544 Mathias Hoffmann and Iryna Shcherbakova, Consumption Risk Sharing over the Business Cycle: the Role of Small Firms' Access to Credit Markets, February 2009

2545 John Beirne, Guglielmo Maria Caporale, Marianne Schulze-Ghattas and Nicola Spagnolo, Volatility Spillovers and Contagion from Mature to Emerging Stock Markets, February 2009

2546 Ali Bayar and Bram Smeets, Economic and Political Determinants of Budget Deficits in the European Union: A Dynamic Random Coefficient Approach, February 2009

2547 Jan K. Brueckner and Anming Zhang, Airline Emission Charges: Effects on Airfares, Service Quality, and Aircraft Design, February 2009

2548 Dolores Messer and Stefan C. Wolter, Money Matters - Evidence from a Large-Scale Randomized Field Experiment with Vouchers for Adult Training, February 2009

2549 Johannes Rincke and Christian Traxler, Deterrence through Word of Mouth, February 2009

2550 Gabriella Legrenzi, Asymmetric and Non-Linear Adjustments in Local Fiscal Policy, February 2009

2551 Bruno S. Frey, David A. Savage and Benno Torgler, Surviving the Titanic Disaster: Economic, Natural and Social Determinants, February 2009

2552 Per Engström, Patrik Hesselius and Bertil Holmlund, Vacancy Referrals, Job Search, and the Duration of Unemployment: A Randomized Experiment, February 2009 
2553 Giorgio Bellettini, Carlotta Berti Ceroni and Giovanni Prarolo, Political Persistence, Connections and Economic Growth, February 2009

2554 Steinar Holden and Fredrik Wulfsberg, Wage Rigidity, Institutions, and Inflation, February 2009

2555 Alexander Haupt and Tim Krieger, The Role of Mobility in Tax and Subsidy Competition, February 2009

2556 Harald Badinger and Peter Egger, Estimation of Higher-Order Spatial Autoregressive Panel Data Error Component Models, February 2009

2557 Christian Keuschnigg, Corporate Taxation and the Welfare State, February 2009

2558 Marcel Gérard, Hubert Jayet and Sonia Paty, Tax Interactions among Belgian Municipalities: Does Language Matter?, February 2009

2559 António Afonso and Christophe Rault, Budgetary and External Imbalances Relationship: A Panel Data Diagnostic, February 2009

2560 Stefan Krasa and Mattias Polborn, Political Competition between Differentiated Candidates, February 2009

2561 Carsten Hefeker, Taxation, Corruption and the Exchange Rate Regime, February 2009

2562 Jiahua Che and Gerald Willmann, The Economics of a Multilateral Investment Agreement, February 2009

2563 Scott Alan Carson, Demographic, Residential, and Socioeconomic Effects on the Distribution of $19^{\text {th }}$ Century US White Statures, February 2009

2564 Philipp Harms, Oliver Lorz and Dieter Urban, Offshoring along the Production Chain, February 2009

2565 Patricia Apps, Ngo Van Long and Ray Rees, Optimal Piecewise Linear Income Taxation, February 2009

2566 John Whalley and Shunming Zhang, On the Arbitrariness of Consumption, February 2009

2567 Marie-Louise Leroux, Endogenous Differential Mortality, Non-Contractible Effort and Non Linear Taxation, March 2009 